\title{
PENGARUH PENERAPAN MANAJEMEN SUMBER DAYA MANUSIA PADA KINERJA ORGANISASI DENGAN MEDIASI MANAJEMEN TALENTA
}

\author{
Agustinus Setyawan \\ ${ }^{1}$ Fakultas Ekonomi, Universitas Internasional Batam, Jalan Gajah Mada, Sei Ladi, Tiban \\ Indah, Sekupang, Kota Batam, Kepulauan Riau 29442 \\ Email: setyawan.agustinus@gmail.com
}

\begin{abstract}
This study aims to investigate the influence of human resource management practices to organization performance and talent management as a mediating factor in the relationship. This research uses methodology with an explanatory study by testing three hypotheses. A hundred managers from several coal companies in East Kalimantan Province are collected as a sample in this research. SEM (Structural Equation Model) is used to analyze the data which is collected by questionnaire. The result of this study found that: (1) Human resource management practices affect talent management positively and significantly; (2) Human resource management practices doesn't affect organization performance significantly; (3) Talent management affects organization performance positively and significant. This research has a managerial implication to guide the decision maker in the company or manager in the human resource management to implement talent management to improve organization performance.
\end{abstract}

Keywords: HRM practices, Talent Management, Organization Performance, structural equation model

\begin{abstract}
Abstrak
Penelitian ini bertujuan untuk meneliti pengaruh penerapan manajemen sumber daya manusia terhadap kinerja organisasi dengan mediasi manajemen talenta. Model persamaan struktural (SEM) digunakan untuk menganalisa data dengan pengujian yang terdiri dati tiga hipotesis. Penelitian menggunakan populasi responden pimpinan perusahaan pertambangan di Kalimantan Timur setingkat manajer dengan pengumpulan data lewat kuesioner dan jumlah sampel yang memenuhi kriteria untuk dianalisa dari 100 pimpinan di berbagai bagian. Penelitian memberikan kesimpulan sebagai berikut: (1) Penerapan manajemen sumber daya manusia berpengaruh positif dan signifikan terhadap manajemen talenta; (2) Penerapan manajemen sumber daya manusia tidak berpengaruh langsung terhadap kinerja organisasi; (3) Manajemen talenta berpengaruh positif dan signifikan terhadap kinerja organisasi. Pengambil keputusan dan pimpinan manajemen sumber daya bisa menggunakan hasil penelitian ini untuk menerapkan strategi manajemen sumber daya dalam bentuk penerapan manajemen talenta untuk meningkatkan kinerja organisasi.
\end{abstract}

Kata Kunci: Penerapan manajemen sumber daya manusia, manajemen talenta, kinerja organisasi, model persamaan struktural. 


\section{PENDAHULUAN}

Kompetisi berdimensi global menjadi tantangan yang serius dan mendasar bagi semua negara dalam era globalisasi saat ini, dimana kompetisi global tersebut mensyaratkan tersedianya sumber daya manusia yang berkualitas dan berwawasan keunggulan yang menurut laporan The Global Competitiveness Index tahun 2016-2017, Indonesia berada pada peringkat 40 dari 138 negara (2015-2016) dan peringkat 37 dari 140 negara (2016-2017). Jika dibandingkan dengan 3 (tiga) negara tetangga seperti Singapura, Malaysia dan Thailand, Indonesia masih tertinggal dari ketiga negara tersebut, di mana Singapura berada pada peringkat 2 (dua) pada periode tahun 2015-2016 dan 2016-2017, Malaysia berada pada peringkat 25 pada tahun 2015-2016 dan peringkat 18 pada tahun 2016-2017, sedangkan Thailand berada pada peringkat 34 pada tahun 2015-2016 dan peringkat 32 pada tahun 2016-2017 (Word Economics Forum). Disamping itu, laporan Global Talent Competitiveness Index tahun 2016-2017, Indonesia berada pada peringkat 90 dari 118 negara dan tertinggal dari 5 (lima) negara tetangga yang tergabung dalam negara ASEAN (Singapura pada peringkat 2, Malaysia pada peringkat 28, Filipina pada peringkat 52 , Thailand pada peringkat 73 , dan Vietnam pada peringkat 86). Global Talent Competitiveness Index mengukur bagaimana pertumbuhan suatu negara, upaya menarik dan mempertahankan talenta, dan menyediakan sumber daya untuk mengembangkan strategi untuk meningkatkan daya saing talenta mereka. Industri pertambangan termasuk tambang batu bara merupakan salah satu industri yang mampu menyerap tenaga kerja yang banyak sehingga strategi manajemen sumber daya manusia menjadi hal yang sangat penting dalam meningkatkan kinerja perusahaan karena erat kaitannya strategi bisnis (Gautam, 2015).

Dalam kaitannya dengan strategi manajemen sumber daya manusia, beberapa literatur sudah melakukan penelitian mengenai variabel mediasi yang mempengaruhi penerapan manajemen sumber daya dan terhadap kinerja organisasi, seperti affective commitment (Al-Hawary dan Alajmi, 2017), human capital (Wright et al., 2011) maupun gabungan keduanya seperti Jiang et al. (2012) dan Raineri (2016). Human capital merupakan representasi individu dari seseorang dalam hal pengetahuan, keahlian dan kemampuan (Becker, 1964; Schultz, 1961), sehingga di dalam organisasi diperlukan pengetahuan baru untuk mendapatkan dan mempertahankan keunggulan kompetitif manajemen talenta (Collings et al., 2018). Manajemen talenta adalah kemampuan dinamis organisasi dalam mengatur pasokan, permintaan, dan aliran talenta yang dimiliki sesuai kompetensi mereka (Pascal, 2004).

Berdasarkan hal-hal di atas, rerangka penelitian ditunjukkan dalam gambar dibawah.

\section{Gambar 1. Rerangka Model Penelitian}

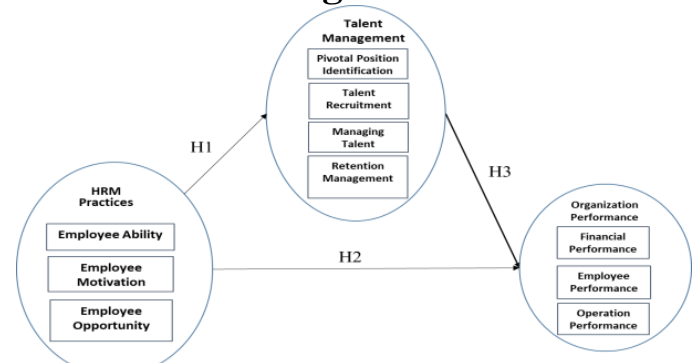

H1: Penerapan Manajemen Sumber Daya Manusia (HRM Practices) mempengaruhi Manajemen Talenta (Talent Management)

H2: Penerapan Manajemen Sumber Daya Manusia (HRM Practices) mempengaruhi Kinerja Organisasi (Organizational Performances) 
H3: Manajemen Talenta (Talent Management) mempengaruhi Kinerja Organisasi (Organizational Performances)

Kinerja organisasi tergantung pada keterampilan, pengetahuan dan pengalaman karyawan untuk mencapai efisiensi, efektivitas, inovasi, kepuasan karyawan dan pelanggan, kualitas produk atau layanan dan kemampuan untuk mempertahankan orang-orang bertalenta yang unik (Absar et al., 2010). Ini telah diukur dalam literatur dari aspek keuangan dan non-keuangan (karyawan dan kinerja operasional). Perspektif keuangan telah digunakan oleh sebagian besar peneliti (Liao \& Wu, 2009; Lopez et al., 2007; Venkatraman dan Ramanujam, 1986), yang mencakup posisi kompetitif, profitabilitas, pertumbuhan penjualan, pangsa pasar dan reputasi organisasi. Demikian pula perspektif non-keuangan, seperti kinerja karyawan (Fuentes et al., 2007), termasuk hal-hal yang berkaitan dengan kepuasan karyawan, perputaran karyawan, tingkat ketidakhadiran dan partisipasi karyawan. Akhirnya, kinerja operasional (Wright et al., 2003; Delaney \& Huselid, 1996; Venkatraman \& Ramanujam, 1986) termasuk jumlah keluhan pelanggan, kualitas layanan dan kepuasan pelanggan. Perspektif keuangan mencakup kinerja keuangan, sedangkan perspektif nonkeuangan mencakup kinerja karyawan dan operasional. Skala Venkatraman \& Ramanujam (1986) telah digunakan untuk mengukur kinerja keuangan dan kinerja operasional. Lebih lanjut, skala Fuentes et al. (2007) telah digunakan untuk mengukur kinerja karyawan (Jyoti \& Sharma, 2012).

Penerapan manajemen sumber daya manusia didefinisikan sebagai kumpulan praktis yang berpengaruh penting pada (keefekktifan kegiatan organisasi (Daspit et al., 2018), dimana manajemen sumber daya fokus pada tiga aspek terkait meliputi kemampuan, motivasi, dan partisipasi karyawan (Kooij dan Boon's, 2018). Dari teori strategi manajemen sumber daya manusia, kinerja yang tinggi dari penerapan manajemen sumber daya manusia akan berpenegaruh pada peningkatan kinerja (Al-Abbadi, 2018). Dengan kata lain, sistem kerja berkinerja tinggi meningkatkan nilai, individualitas, dan kemampuan pengetahuan dan keterampilan karyawan, yang pada gilirannya menghasilkan keunggulan kompetitif dan kinerja yang lebih baik (Zhang \& Morris, 2014), yaitu kinerja keuangan (Huselid, 1995), kinerja karyawan (Xiaomei et al., 2013) dan kinerja operasional (Kintana et al., 2006). Lebih lanjut, Hassan et al. (2013) mengungkapkan bahwa sistem kerja berkinerja tinggi, termasuk pelatihan, penilaian dan pemberdayaan, memainkan peran penting dalam meningkatkan loyalitas karyawan dan kinerja keuangan. Penggunaan model AMO (Ability, Motivation, Opportunity) dalam sistem kerja berkinerja tinggi dapat meningkatkan kinerja karyawan (Boxall \& Purcell, 2003) dengan menerapkan sistem insentif (Huang et al., 2016). Ini mengurangi perputaran karyawan (employee turnover) dan meningkatkan produktivitas, yang pada gilirannya memiliki efek positif pada kinerja keuangan perusahaan (Zhang \& Morris, 2014). Misalnya, sistem kerja berkinerja tinggi meningkatkan pengetahuan dan tingkat keterampilan karyawan melalui inisiatif berbasis kemampuan. Ini memotivasi mereka melalui umpan balik kinerja yang teratur, insentif dan penghargaan. Lebih jauh, partisipasi dalam proses pengambilan keputusan memberi mereka kesempatan untuk memperluas ide-ide inovatif yang memfasilitasi untuk meningkatkan posisi kompetitif organisasi, meraih laba yang lebih tinggi, tingkatkan volume penjualan, pangsa pasar, serta meningkatkan reputasi organisasi. Demikian pula, Kintana et al. (2006) 
mengakui bahwa sistem kerja berkinerja tinggi meningkatkan pengetahuan karyawan, keterampilan dan memberdayakan tenaga kerja yang berkomitmen, yang meningkatkan kinerja operasional organisasi. Berbagai peneliti telah mengungkapkan dampak positif dari keterampilan, motivasi dan meningkatkan peluang praktik sumber daya manusia pada kinerja organisasi, pertumbuhan penjualan, profitabilitas, perputaran karyawan, tingkat kepuasan, kualitas layanan dan kinerja secara keseluruhan (Obeidat et al., 2016 ; Gong et al., 2009; Akhtar et al., 2008; Guerrero \& BarraudDidier, 2004). Lebih lanjut, hasil serupa telah ditemukan di sektor bisnis/manufaktur (Katou \& Budhwar, 2006; Liao, 2005) serta di sektor jasa (Muduli, 2015). Misalnya, peningkatan keterampilan praktik manajemen sumber daya manusia, seperti pelatihan ekstensif, membantu dalam meningkatkan kinerja karyawan (Birdi et al., 2008) yang meningkatkan kinerja organisasi. Demikian pula, praktik pengembangan kompetensi meningkatkan efisiensi.

$$
\text { Manajemen talenta adalah }
$$

kemampuan dinamis di mana perusahaan merasakan, merebut, dan mengubah keterampilan, sumber daya, dan kompetensi mereka (Linden \& Teece, 2014). Menurut Ambrosini dan Bowman (2009), kemampuan dinamis terfokus pada masa depan dan mengembangkan basis sumber daya yang paling memadai, nilai mereka berasal dari output mereka. Landasan penerapan manajemen sumber daya manusia, diterapkan pada seluruh tenaga kerja terutama terdiri dari kemampuan biasa atau dasar (Fainshmidt et al., 2016; Winter, 2003). Kemampuan dasar ini hanya memungkinkan organisasi berfungsi sehari-hari (Helfat \& Winter, 2011). Namun, mereka menyediakan platform yang stabil untuk mengembangkan kemampuan dinamis, yang kemudian bertindak sebagai mekanisme transmisi meningkatkan kemampuan biasa dan membangun basis sumber daya berkelanjutan baru (Ambrosini \& Bowman, 2009; Schilke, 2014; Teece, 2014). Dengan demikian, manajemen talenta dapat dilihat sebagai mekanisme transmisi yang memungkinkan organisasi untuk terus berubah (Rindova \& Kotha, 2001). Fainshmidt et al. (2016) dan Weerawardena, Mort, Liesch, \& Knight (2007) menunjukkan bahwa kemampuan dinamis di pasar negara berkembang menghasilkan manfaat yang unggul karena mereka cenderung langka dan dapat memberikan nilai lebih di turbulen kondisi perekonomian.

\section{METODE PENELITIAN}

Sekaran dan Bougie (2016) menyatakan bahwa uji hipotesis meneliti hubungan antara dua atau lebih variabel yang dinyatakan dalam bentuk pernyataan yang mewakili tiap variabel sehingga dapat diperoleh kesimpulan dari penelitian yang dilakukan. Lebih lanjut Sekaran dan Bougie (2016) menjelaskan bahwa mengumpulkan informasi dari orang-orang untuk menggambarkan, membandingkan, atau menjelaskan tentang pengetahuan, sikap dan perilaku mereka merupakan suatu strategi yang dilakukan dalam penelitian survei. Sekaran dan Bougie (2016) juga menjelaskan bahwa beberapa manajer merupakan perwakilan perusahaan yang merupakan unit analisis dalam penelitian. Penelitian ini dilakukan dalam periode Oktober 2018 - Maret 2019 yang menurut Sekaran \& Bougie (2016) termasuk penelitian cross sectional dimana data hanya sekali dikumpulkan dalam periode tertentu.

Penelitian menggunakan populasi para pimpinan setingkat manajer pada perusahaan pertambangan di Kalimantan Timur. Ada seratus lima puluh kuesioner yang disebarkan dan diperoleh 100 data yang layak dilakukan penelitian lebih lanjut. Dalam bukunya, Hair et al. (2018) 
menyatakan bahwa MLE (maximum likelihood estimation) memberikan hasil yang valid dan stabil dengan jumlah sampel paling kecil 50 atau ukuran sampel antara 100 sampai 400 disarankan dengan berbagai pertimbangan. Selanjutnya, Hair et al. (2018) menjelaskan bahwa minimum sampel 100 dibutuhkan untuk model dengan maksimal lima variabel, modest communalities (.5), dan tidak ada variabel yang tidak teridentifikasi.

Empat belas item pernyataan yang diadaptasi dari Tian et al (2016) digunakan untuk mengukur penerapan manajemen sumber daya manusia, dimana item 1 (satu) sampai dengan 5 (lima) menjelaskan tentang dimensi kemampuan karyawan (employee ability), item 6 (enam) sampai dengan 10 (sepuluh) menjelaskan tentang dimensi motivasi karyawan (employee motivation), dan item 11 (sebelas) sampai dengan 14 (empat belas) menjelaskan tentang kesempatan karyawan (employee opportunity). Disamping itu, empat belas item pernyataan yang diadaptasi dari Mensah (2015) digunakan untuk mengukur manajemen talenta, dimana item 1 (satu) sampai dengan 4 (empat) menjelaskan tentang dimensi identifikasi posisi penting (pivotal position identification), item 5 (lima) sampai dengan 7 (tujuh) menjelaskan tentang dimensi perekrutan talenta (talent recruitment), item 8 (delapan) sampai dengan 10 (sepuluh) menjelaskan tentang pengelolaan talenta (managing talent), dan item 11 (sebelas) sampai dengan 14 (empat belas) menjelaskan tentang manajemen retensi (retention management), sedang pengukuran kinerja organisasi menggunakan 12 (dua belas) item pernyataan yang diadaptasi dari Tseng (2016), Jyoti dan Rani (2017), dan Wang et al. (2016), dimana item 1 (satu) sampai dengan 4 (empat) menjelaskan tentang kinerja keuangan, item 5 (lima) sampai dengan 8 (delapan) menjelaskan tentang kinerja karyawan, dan item 9 (sembilan) sampai dengan 12 (dua belas) menjelaskan tentang kinerja operasional.

Gambar berikut menunjukkan model persamaan struktur.

\section{Gambar 2. Model Persamaan Struktur}

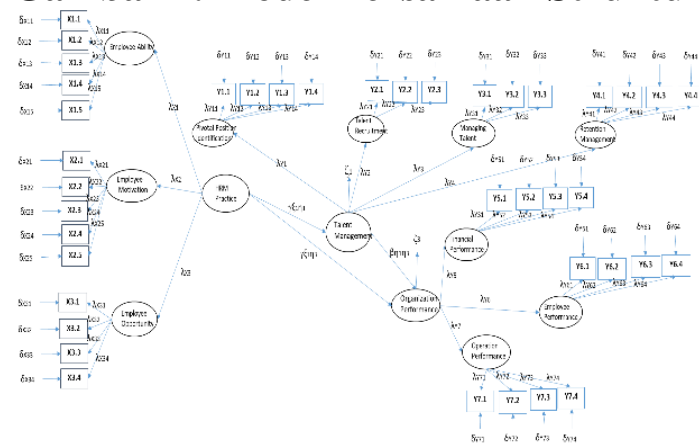

ANALISA DATA

Tabel 1. Profil Responden

\begin{tabular}{lcc}
\hline & Frekuensi & $\%$ \\
\hline Gender & & \\
Male & 96 & 96.0 \\
Female & 4 & 4.0 \\
Education & & \\
< Degree & 6 & 6.0 \\
Degree & 82 & 82.0 \\
Master & 12 & 12.0 \\
Working & & \\
<5 years & 22 & 22.0 \\
$5-10$ years & 28 & 28.0 \\
$>$ 10 years & 50 & 50.0 \\
Total & & \\
<5 years & 1 & 1.0 \\
5 - 10 years & 7 & 7.0 \\
$>10$ years & 92 & 92.0 \\
\hline Sumber: SPSS 22.0 & &
\end{tabular}

Persepsi responden terhadap penerapan manajemen sumber daya manusia, manajemen talenta, dan kinerja organisasi ditunjukkan di tabel 2, 3 dan 4 .

Tabel 2. Penerapan Manajemen Sumber Daya Manusia

\begin{tabular}{|c|c|c|c|}
\hline Dimensi & Indikator & SD & Mean \\
\hline \multirow{3}{*}{ EA } & $\mathrm{X} 11$ & 3.98 & 0.8874 \\
\cline { 2 - 4 } & $\mathrm{X} 12$ & 4.16 & 0.8130 \\
\cline { 2 - 4 } & $\mathrm{X} 13$ & 4.02 & 0.8285 \\
\cline { 2 - 4 } & $\mathrm{X} 14$ & 4.48 & 0.6739 \\
\cline { 2 - 4 } & $\mathrm{X} 15$ & 3.83 & 0.8883 \\
\hline \multirow{4}{*}{ EM } & $\mathrm{X} 21$ & 4.53 & 0.5938 \\
\cline { 2 - 4 } & $\mathrm{X} 22$ & 4.27 & 0.9195 \\
\cline { 2 - 4 } & $\mathrm{X} 23$ & 4.38 & 0.7217 \\
\cline { 2 - 4 } & $\mathrm{X} 24$ & 4.00 & 0.7914 \\
\cline { 2 - 4 } & $\mathrm{X} 25$ & 4.54 & 0.6423 \\
\hline
\end{tabular}




\begin{tabular}{|c|c|c|c|}
\hline \multirow{4}{*}{ EO } & X31 & 4.03 & 0.7311 \\
\hline & X32 & 3.91 & 0.9311 \\
\hline & X33 & 3.03 & 1.0489 \\
\hline & X34 & 3.73 & 0.7086 \\
\hline & & 4.06 & 0.7985 \\
\hline
\end{tabular}

Sumber: Hasil Pengolahan dengan SPSS 22.0

Tabel 3. Manajemen Talenta

\begin{tabular}{|c|c|c|c|}
\hline Dimensi & Indikator & SD & Mean \\
\hline \multirow[t]{4}{*}{ PPI } & Y11 & 3.82 & 0.6094 \\
\hline & Y12 & 3.76 & 0.5881 \\
\hline & Y13 & 3.78 & 0.5610 \\
\hline & Y14 & 3.60 & 0.7386 \\
\hline \multirow[t]{3}{*}{ TR } & Y21 & 3.71 & 0.7426 \\
\hline & Y22 & 3.67 & 0.6825 \\
\hline & Y23 & 3.83 & 0.7528 \\
\hline \multirow{3}{*}{ MT } & Y31 & 3.57 & 0.7818 \\
\hline & Y32 & 3.67 & 0.6825 \\
\hline & Y33 & 3.74 & 0.7470 \\
\hline \multirow{4}{*}{$\mathrm{RM}$} & Y41 & 2.84 & 0.9181 \\
\hline & Y42 & 4.17 & 0.6825 \\
\hline & Y43 & 4.25 & 0.7160 \\
\hline & Y44 & 3.81 & 0.8842 \\
\hline \multicolumn{2}{|c|}{ TM } & 3.73 & 0.7205 \\
\hline
\end{tabular}

Sumber: Hasil Pengolahan dengan SPSS 22.0

Tabel 4. Kinerja Organisasi

\begin{tabular}{|c|c|c|c|}
\hline Dimensi & Indikator & SD & Mean \\
\hline \multirow[t]{4}{*}{ FP } & Y51 & 3.89 & 0.6497 \\
\hline & Y52 & 3.89 & 0.6948 \\
\hline & Y53 & 3.59 & 0.7399 \\
\hline & Y54 & 3.66 & 0.6849 \\
\hline \multirow[t]{4}{*}{$\mathrm{EP}$} & Y61 & 3.48 & 0.8100 \\
\hline & Y62 & 3.65 & 0.9143 \\
\hline & Y63 & 3.62 & 1.0520 \\
\hline & Y64 & 3.64 & 0.7456 \\
\hline \multirow{4}{*}{ OPP } & Y71 & 3.90 & 0.6435 \\
\hline & Y72 & 3.96 & 0.6952 \\
\hline & Y73 & 3.84 & 0.7208 \\
\hline & Y74 & 3.73 & 0.7086 \\
\hline \multicolumn{2}{|c|}{ OP } & 3.74 & 0.7549 \\
\hline
\end{tabular}

Sumber: Hasil Pengolahan dengan SPSS 22.0

Dengan menggunakan rujukan dari

Hair et al. (2018), maka semua indikator dinyatakan valid dan reliabel karena faktor beban $\lambda \geq 0.5$, nilai rata-rata $\mathrm{VE} \geq$ 0.5 dan nilai reliabilitas kontruk $\geq 0.6$. Uji kesesuaian model (Goodness of Fit) dijelaskan di tabel 5.
Tabel 5. Uji Kelayakan Model (GOF)

\begin{tabular}{|c|c|c|c|}
\hline $\begin{array}{c}\text { Indikator } \\
\text { Kelayakan } \\
\text { Model } \\
\text { (GOF) }\end{array}$ & $\begin{array}{c}\text { Ukuran } \\
\text { yang } \\
\text { diharapkan }\end{array}$ & $\begin{array}{c}\text { Hasil } \\
\text { Estimasi }\end{array}$ & Kesimpulan \\
\hline \multicolumn{4}{|c|}{ Ukuran Absolute Fit } \\
\hline RMSEA & $0.05-0.08$ & 0,074 & $\begin{array}{c}\text { Dapat } \\
\text { diterima }\end{array}$ \\
\hline GFI & $>0.80,>0.90$ & 0.83 & $\begin{array}{c}\text { Dapat } \\
\text { diterima }\end{array}$ \\
\hline \multicolumn{4}{|c|}{ Ukuran Incremental Fit } \\
\hline NNFI & $>0.90$ & 0.93 & Good fit \\
\hline CFI & $>0.90$ & 0.95 & Good fit \\
\hline IFI & $>0.90$ & 0.95 & Good fit \\
\hline NFI & $>0.80,>0.90$ & 0.90 & Good fit \\
\hline \multicolumn{4}{|c|}{ Ukuran Parsimony Fit } \\
\hline $\begin{array}{l}\text { AIC dan } \\
\text { CAIC }\end{array}$ & $\begin{array}{c}\text { Nilai model } \\
<\text { model } \\
\text { saturated }\end{array}$ & $\begin{array}{c}\text { AIC: } \\
207.10 \\
\text { CAIC: } \\
210.0\end{array}$ & Good Fit \\
\hline ECVI & $\begin{array}{c}\text { Nilai default } \\
\text { model < } \\
\text { model } \\
\text { saturated }\end{array}$ & $\begin{array}{c}2.09< \\
2.12\end{array}$ & Good Fit \\
\hline
\end{tabular}

Sumber: Hasil Pengolahan dengan LISREL 8.8

Untuk menunjukkan bahwa model fit dan bisa dilakukan proses selanjutnya, maka musti ada yang memenuhi kriteria kelayakan model dari tiap ukuran (Hair et al., 2018). Model layak untuk dilakukan pengujian selanjutnya merujuk pada kriteria kelayakan yang dipenuhi di tiap indikator kelayakan model.

Dari hasil uji hipotesa dengan Lisrel 8.8, diperoleh hasil seperti tabel 6 dibawah:

Tabel 6.Hasil Pengujian Hipotesa

\begin{tabular}{|c|c|c|c|}
\hline Hipotesis & $\begin{array}{c}\text { Koefisien } \\
\gamma / \beta\end{array}$ & Nilai t & Simpulan \\
\hline H1 & 0.41 & 2.16 & H1 diterima \\
\hline H2 & -0.44 & -1.22 & H2 ditolak \\
\hline H3 & 1.72 & 2.58 & H3 diterima \\
\hline
\end{tabular}

Sumber: Hasil pengolahan SEM dengan Lisrel 8.8

\section{SIMPULAN}

Kesimpulan dari penelitian secara umum adalah strategi manajemen sumber daya dalam bentuk manajemen talenta diperlukan dalam meningkatkan kinerja perusahaan pertambangan di Kalimantan 
Timur dan berfungsi sebagai mediasi penuh (full mediation). Implikasi penelitian menjadi rujukan akan perlunya variabel mediasi dalam hubungan penerapan manajemen sumber daya manusia dalam meningkatkan kinerja organisasi seperti penelitian Al-Hawary dan Alajmi (2017), Wright et al. (2011) maupun Jiang et al. (2012) dan Raineri (2016).

\section{DAFTAR PUSTAKA}

Absar, M. N., Nimalathasan, B., and Jilani, M. A. K. (2010). Impact of HR practices on organizational performance in Bangladesh. International Journal of Business and Information Technology, 3, 1519.

Akhtar, S., Ding, D. Z. and Ge, G. L. (2008). Strategic HRM practices and their impacts on company performance in Chinese enterprises. Human Resource Management, 47(1), 15-32.

Al-Abbadi, L. H. M. (2018). The Impact of High Performance Human Resources Practices on In-Role and Innovative Job Performance: The Mediation Role of Affective Commitment. Global Journal of Management and Business Research: A Administration and Management, 18(4), 52-65.

Al-Hawary, S., \& Alajmi, H. (2017). Organizational Commitment of the Employees of the Ports Security Affairs of the State of Kuwait: The Impact of Human Recourses Management Practices. International Journal of Academic Research in Economics and Management Sciences, 6(1), 52-78.

Amrosini, V., \& Bowman, C. (2009). What are dynamic capabilities and are they a useful construct in strategic management? International Journal of Management Review, 11(1), 29-49
Becker, G. S. 1964. Human capital. New York, NY: Columbia University Press.

Birdi, K., Clegg, C., Patterson, M., Robinson, A., Stride, C., Wall, T., \& Wood, S. (2008). The impact of human resource and operational management practices on company productivity: a longitudinal study. Personnel Psychology, 61(3), 467501.

Boxall, P., \& Purcell, J. (2003). Strategy and Human Resource Management. Palgrave Macmillan, Basingstoke

Collings, D. G., Mellahi, K., \& Cascio, W. F. (2018). Global Talent Management and Performance in Multinational Enterprises: A Multilevel Perspective. Journal of Management, 20(10), 1-27.

Daspit, J., Madison, K., Barnett, T., and Long, R. (2018). The emergence of bifurcation bias from unbalanced families: Examining HR practices in the family firm using circumflex theory. Human Resource Management Review, 28(1), 18-32.

Delaney, T. J., \& Huselid, M. A. (1996). The Impact of Human Resource Practices on Perceptions Organizational Performance. The Academy of Management Journal, 39(4), 949-969.

Fainshmidt, S., Pezeshkan, A., Frazier, M. L., Nair, A., \& Markowski, E. (2016). Dynamic capabilities and organizational performance: A metaanalytic evaluation and extension. Journal of Management Studies, 53(8), 1348-1380.

Fuentes, D., Disante, K.B., Valdecantos, A., Cortina, J., Vallejo, V.R., 2007. Response of Pinus halepensis Mill. seedlings to biosolids enriched with $\mathrm{Cu}, \mathrm{Ni}$ and $\mathrm{Zn}$ in three Mediterranean forest soils. Environ. Poll. 141, 324-331.

Gautam, D.K. (2015). Strategic integration of HRM for 
organizational performance: Nepalese reality. South Asian Journal of Global Business Research, 4(1), 110-128.

Gong, Y., Law, K. S., Chang, S., \& Xin, K. R. (2009). Human resources management and firm performance: the differential role of managerial affective and continuance commitment. Journal of Applied Psychology, 94(1), 263-275.

Guerrero, S., \& Barraud-Didier, V. (2004). High-involvement practices and performance of French firms. The International Journal of Human Resource Management, 15(8), 14081423.

Hair, J. F., Babin, B. J., Anderson, R. E., \& Black, W. C. (2018). Multivariate Data Analysis. $8^{\text {th }}$ Edition. New Jersey: Pearson Prentice Hall.

Hassan, M. U., Nawaz, M. S., Abbas, G., \& Sajid, M. I. (2013). Impact of high performance work practices on employee loyalty and financial performance through mediation of employee satisfaction: An empirical evidence from the financial sector of Pakistan. Middle-East Journal of Scientific Research, 16(8), 10371046.

Helfat, E. C., \& Winter, S. G. (2011). Untangling dynamic and operational capabilities: Strategy for the $(\mathrm{N})$ ever changing world. Strategic Management Journal, 32(11), 12431250.

Huselid, M. A. (1995). The Impact of Human Resource Management Practices on Turnover, Productivity, and Corporate Financial Performance. Academy of Management Journal, 38(3), 635872.

Jiang, K., Lepak, D. P., Hu, J. \& Baer, J. C. (2012). How does human resource management influence organizational outcomes? A meta-analytic investigation of mediating mechanisms. Academy of Management Journal, 55(6), 12641294.

Jyoti, J., \& Sharma, J. (2012). Impact of Market Orientation on Business Performance: Role of Employee Satisfaction and Customer Satisfaction. Vision, 16(4), 297-313.

Jyoti, J., \& Rani, A. (2017). High performance work system and organization performance: role of knowledge management. Personnel Review, 46(8), 1770-1795.

Katou, A. A., \& Budhwar, P. S. (2006). Human resource management systems and organisational performance: a test of a mediating model in the Greek manufacturing context. International Journal of Human Resource Management, 17(7), 1223-1253.

Kintana, M. L., Alonso, A. U., \& Olaverri, C. G. (2006) Highperformance work systems and firms' operational performance: the moderating role of technology. The International Journal of Human Resource Management, 17(1), 70-85.

Kooij, D., \& Boon, C. (2018). Perceptions of HR practices, personorganization fit, and affective commitment: The moderating role of career stage. Human Resource Management Journal, 28(1), 61-75.

Liao, S. Y. (2005). Business strategy and performance: the role of human resource management control. Personnel Review, 34(3), 294-309.

Liao, S-h., \& Wu, C-c. (2009). The Relationship among Knowledge Management, Organizational Learning, and Organizational Performance. International Journal of Business and Management, 4(4), 64-76.

Linden, G., \& Teece, D. (2014). Managing expert talent. In P. Sparrow, H. Scullion, \& I. Tarique 
(Eds). Strategic talent management: Contemporary issues in international context, Cambridge: Cambridge University Press, 87-116.

Lopez, V., Rodriguez, L., \& Garcia, A. (2007). Sustainable Development and Corporate Performance: A Study Based on the Dow Jones Sustainability Index. Journal of Business Ethics, 75(3), 285-300.

Mensah, J.K. (2015). A "Coalesced framework" of talent management and employee performance: For further research and practice. International Journal of Productivity and Performance Management, 64(4), 544-566.

Muduli, A. (2015). High performance work system, HRD climate and organisational performance: an empirical. European Journal of Training and Development, 39 (3), 239-257.

Obeidat, S.M., Mitchell, R., \& Bray, M. (2016). The link between high performance work practices and organizational performance: Empirically validating the conceptualization of HPWP according to the AMO model. Employee Relations, 38(4), 578-595.

Pascal, C. (2004), "Foreword", in Schweyer, A. (Ed.), Talent Management Systems: Best Practices in Technology Solutions for Recruitment, Retention, and Workforce Planning, Wiley, 9-13

Ranieri, A. (2016). Linking human resources practices with performance: the simultaneous mediation of collective affective commitment and human capital. The International Journal of Human Resource Management, 1-30

Rindova, V. P., \& Kotha, S. (2001). Continuous "morphing": Competing through dynamic capabilities, form, and function. Academy of
Management Journal, 44(6), 12631280.

Schilke, O. (2014). Second-order dynamic capabilities: How do they matter? Academy of Management Perspective, 28(4), 368-380.

Sekaran, U., \& Bougie, R. (2016). Research methods for business: a skill-building approach. 7th Edition. Chichester: John Wiley \& Sons.

Teece, D. J. (2014). The foundation of enterprises performance: Dynamic and ordinary capabilities in an (economic) theory of firms. Academy of Management Perspectives, 28(4), 328-352.

Tian, A.W., Cordery, J., \& Gamble, J. (2016). Staying and Performing: How human resource management practices increase job embeddedness and performance. Personal Review, 45 (5), 947-968.

Tseng, S.M. (2016). The effect of knowledge management capability and customer knowledge gaps on corporate performance. Journal of Enterprise Information Management, 29(1), 51-71.

Venkatraman, N., \& Ramanujam, V. (1986). Measurement of Business Performance in Strategy Research: A Comparison of Approaches. The Academy of Management Review, 11(4), 801-814.

Wang, Z., Wang, N., Cao, J., \& Ye, X. (2016). The impact of intellectual capital -knowledge management strategy fit on firm performance. Management Decision, 54(8), 18611885.

Weerawardena, J., Mort, G. S., Liesch, P. W., \& Knight, G. (2007). Conceptualizing accelerated internationalization in the born global form: A dynamic capabilities perspective. Journal of World Business, 42(3), 294-306.

Winter, S. G. (2003). Understanding dynamic capabilities. Strategic 
Management Journal, 24(10), 991995.

Wright, P., Moynihan, L. M., \& Gardner, T. (2003). The Impact of HR Practices on the Performance of Business Units. Human Resource Management Journal, 13(3), 21-36.

Wright, P., Gardner, T., Moynihan, L. and Allen, M. (2005). The relationship between HR practices and firm performance: Examining causal order. Personnel psychology, 58(2), 409-446.

Xiaomei, Z., Kong, L., \& Zhou, H. (2013). Effects of high performance work systems on employee performance: psychological contract breach as mediator. International Academic Workshop on Social Science, 152-156.

Zhang, B., \& Morris, C. (2014). Highperformance work systems and organizational performance: testing the mediation role of employee outcomes using evidence from PR China. The International Journal of Human Resource Management, 25(1), 1-23. 